\title{
Bipolar hemiarthroplasty for stage III sickle cell-related avascular necrosis of the femoral head: a successful alternative to total hip replacement
}

\author{
YZ Lawal, ${ }^{1}$ MI Maitama, ${ }^{2}$ FS Ejagwulu, ${ }^{2}$ LI Dahiru, ${ }^{2}$ M Nattawa, ${ }^{3}$ A Lawal ${ }^{4}$ \\ MBBS(ABU), FWACS, FAOI, Consultant and lecturer, Orthopaedic surgery, Ahmadu Bello University Zaria \\ MBBS, FWACS, Consultant and lecturer, Orthopaedic surgery, Ahmadu Bello University Zaria \\ MBBS, FWACS, Consultant orthopaedic surgeon, Federal Medical Centre, Katsina \\ ${ }_{4}$ MBBS, FWACP, Consultant and lecturer, Community Medicine, Ahmadu Bello University Zaria
}

Corresponding author: Dr YZ Lawal, Department of Orthopaedic Surgery, Ahmadu Bello University Zaria, Nigeria, Email: lawalyau@yahoo.co.uk

\begin{abstract}
Introduction: The purpose of this study is to bring to the fore a simple, less expensive, biomechanically sound means of treating a devastating complication of sickle cell disease (SCD). SCD is a neglected haemoglobinopathy which is the most common cause of morbidity and mortality due to a genetic disorder. Avascular necrosis of the femoral head seen in sicklers is treated by total hip replacement which is expensive and fraught with complications of infection and revision in sickle cell patients. The simple bipolar hemiarthroplasty is easier to perform, less expensive, and relieves the patient of pain and limitation of movement.

Methods: All patients seen by one of the contributors with stage III Ficat and Arlet avascular necrosis of the femoral head (AVNFH) were assessed for pain and limitation of movement using the numeric rating scale (NRS) for pain and walking distance in metres. These were recorded. Patients were then operated on the hip via the anterolateral approach of Watson Jones. A bipolar endoprosthesis is inserted and the hip repaired. Post-operative NRS for pain and walking distances were measured and recorded. Complications such as infection, protrusion acetabula, and dislocation were also noted.

Results: The mean pre-operative walking distance was 172 metres with the highest being 400 and the lowest 50 metres. The mean post-operative walking distance was 614 metres indicating a more than three times improvement in the ability to walk long distances. The improvement was gradual and increased with time. The mean pre-operative NRS for pain was 6 with a range of 5 to 9 . The average post-operative NRS was 3 indicating a two-fold decline in intensity of pain when sitting or walking.
\end{abstract}

Conclusions: Bipolar hemiarthroplasty is a useful, successful modality of treatment for stage III osteonecrosis of the femoral head in SCD patients in low income countries.

Key words: avascular necrosis, femoral head, bipolar endoprosthesis, hemiarthroplasty

Citation: Lawal YZ, Maitama MI, Ejagwulu FS, Dahiru LI, Nattawa M, Lawal A. Bipolar hemiarthroplasty for stage III sickle cell-related avascular necrosis of the femoral head, a successful alternative to total hip replacement. SAOJ 2017;16(3):31-34. DOI 10.17159/2309-8309/2017/v16n3a3

Editor: Prof Anton Schepers, University of the Witwatersrand

Received: September 2016 Accepted: December 2016 Published: August 2017

Copyright: () 2017 Lawal YZ, et al. This is an open-access article distributed under the terms of the Creative Commons Attribution Licence, which permits unrestricted use, distribution and reproduction in any medium, provided the original author and source are credited.

Funding: Nil.

Conflict of interest: There are no conflicts of interest with respect to all the authors. 


\section{Introduction}

Sickle cell disease (SCD)-related avascular necrosis (AVN) or osteonecrosis of the femoral head is a disease that affects quite a significant proportion of young sicklers. At the early stage of the disease, the articular cartilage of the head of femur and acetabula are normal. The diagnosis of avascular necrosis of the femoral head (AVNFH) is clinical and confirmed by plain anteroposterior pelvic $\mathrm{X}$-rays. Early diagnosis may be made with the use of computerised tomograms (CT) and magnetic resonance imaging (MRI) which are more sensitive diagnostic tests but are expensive and therefore, rarely employed. SCD is the most common cause of femoral head necrosis in black people. ${ }^{1}$ It is rare to make an early diagnosis, hence the preponderance in later stages of the disease of the need for more complex surgical procedures like total hip replacement (THR). When the condition is not managed quickly and appropriately, it leads to the collapse of the femoral head and osteoarthritis. Pain and limitation of movement are the main features of this condition and can be seen in passive and active movement followed by alteration in gait. Currently, THR is the gold standard treatment offered to these patients in high income countries where it is affordable, albeit with equivocal results. In the early days when THR in sicklers was not as common, this was true. Our current experience does not suggest that. Core decompression and intertrochanteric osteotomy are not effective when collapse has already occurred..$^{2,3}$ Other methods of treating the condition, such as reconstructing the femoral head using autologous iliac bone grafts, vascularised fibular grafts, and muscle pedicle bone grafts, are laborious in our environment and require multiple hospitalisations with increased costs. It also requires expertise and equipment which we do not have. ${ }^{4}$

Low viscosity bone cement injection has been attempted with good early results but this technique has not gained widespread acceptance. ${ }^{1,5}$ Primary bipolar hemiarthroplasty has been used in the treatment of unstable inter-trochanteric fractures in elderly osteoporotic patients. It was found to be less associated with morbidity of infection, blood loss and dislocations compared to THR. It is also less expensive, has a shorter operating time, and a less steep learning curve than THR. ${ }^{6}$ It is our aim to demonstrate the efficacy of a simple, uncemented bipolar endoprosthesis to treat grade III AVNFH in resource-constrained settings as an alternative to THR.

\section{Materials and methods}

Patients with Ficat stage III osteonecrosis of the femoral head and background SCD were treated by bipolar hemiarthroplasty. Eighteen patients were operated on. Diagnosis of SCD was made by haemoglobin electrophoresis and the AVNFH confirmed by plain anteroposterior pelvic radiographs. Pain and limitation of movement were the two most important symptoms. We used simple means of assessing pain because we felt the Harris hip score needs modification to fit our mainly illiterate patients who live in poorly planned towns and villages. The degree of pain is estimated by a numeric rating score (NRS) for pain. We recorded walking distance as a function of limitation of movement, which was estimated by the patient's ability or inability to walk a distance of one kilometre. These parameters were measured and recorded (Table I).

Pre-operative preparation included complete blood count, urea, electrolytes, and grouping and cross-matching of blood. Three patients had exchange blood transfusion before their operations. All patients were operated under spinal anaesthesia with the hip approached through the anterolateral incision. Intra-operative blood salvage was not employed but the blood loss was estimated for each patient. The femoral neck was osteotomised in situ or with the hip dislocated in situations where possible. Femoral preparation involved the use of rasping the medullary cavity using different sizes of femoral broaches and reamers. The ease with which medullary cavity preparation was done was noted. The medullary cavity was lavaged with saline and the bipolar endoprosthesis femoral stem gradually introduced by impaction. The hip was lavaged with saline and inspected before reduction. Wounds were closed in layers with a vacuum drain in situ. The patients were followed up at four weeks after discharge where the walking distance and degree of pain were measured. The first measurement was at four weeks and then subsequently every four weeks. Complications such as infection, dislocation, protrusion acetabula, and persistent pain were sought and recorded. Graphs of the pre-operative and post-operative walking distances were drawn up. Follow-up was for a minimum period of one year.

The mean difference, standard deviation, standard error of mean, $95 \%$ confidence interval, $t$ value $D f$ and $p$ values were calculated for the pre-operative and post-operative walking distance and the pre-operative and post-operative numerical score for pain and recorded in Table II.

\section{Results}

There were ten male patients and eight female patients. The average age for females was 24 years and 18 for males. Seven affected hips were on the right and 11 on the left. Patients' hip-related characteristics are given in Table I. There were no other comorbidities such as hypertension or diabetes mellitus. The average operating time was two hours. One patient had intra-operative perforation of the proximal femur; she went on to have a deep infection necessitating the removal of the implant. There were no cases of dislocation of the hip and no protrusion acetabula. Two patients had persistent pain in the hip and thigh which was controlled by analgesics. None of the patients needed polymethylmethacrylate augmentation. The mean pre-operative walking distance was 172 metres with the highest being 400 and the lowest 50 metres.

Table I: Pre-operative and post-operative patient characteristics

\begin{tabular}{|c|c|c|c|c|c|}
\hline $\begin{array}{l}\text { Patient } \\
\text { number }\end{array}$ & $\begin{array}{l}\text { Degree of } \\
\text { osteo- } \\
\text { necrosis } \\
\text { Ficat } \\
\text { stage }\end{array}$ & $\begin{array}{c}\text { Pre- } \\
\text { operative } \\
\text { NRS }\end{array}$ & $\begin{array}{l}\text { Post- } \\
\text { operative } \\
\text { NRS }\end{array}$ & $\begin{array}{c}\text { Pre- } \\
\text { operative } \\
\text { walking } \\
\text { distance } \\
\text { (m) }\end{array}$ & $\begin{array}{c}\text { Post- } \\
\text { operative } \\
\text { walking } \\
\text { distance } \\
\text { (m) }\end{array}$ \\
\hline 1 & III & 6 & 3 & 100 & 650 \\
\hline 2 & III & 5 & 3 & 300 & 600 \\
\hline 3 & III & 7 & 2 & 200 & 600 \\
\hline 4 & III & 6 & 5 & 100 & 700 \\
\hline 5 & III & 7 & 3 & 150 & 500 \\
\hline 6 & III & 7 & 2 & 200 & 700 \\
\hline 7 & III & 8 & 2 & 100 & 700 \\
\hline 8 & III & 5 & 2 & 300 & 600 \\
\hline 9 & III & 5 & 2 & 300 & 600 \\
\hline 10 & III & 7 & 4 & 150 & 700 \\
\hline 11 & III & 9 & 0 & 50 & 1000 \\
\hline 12 & III & 6 & 2 & 100 & 700 \\
\hline 13 & III & 7 & 4 & 150 & 400 \\
\hline 14 & III & 6 & 3 & 150 & 500 \\
\hline 15 & III & 5 & 3 & 400 & 500 \\
\hline 16 & III & 6 & 3 & 150 & 500 \\
\hline 17 & III & 7 & 4 & 100 & 600 \\
\hline 18 & III & 7 & 4 & 100 & 500 \\
\hline $\begin{array}{l}\text { Average } \\
\text { score }\end{array}$ & III & 6 & 3 & 172 & 614 \\
\hline
\end{tabular}


Table II: Statistical parameters

\begin{tabular}{|c|c|c|c|c|c|c|c|c|}
\hline & & $\begin{array}{c}\text { Mean } \\
\text { difference }\end{array}$ & $\begin{array}{l}\text { Standard } \\
\text { deviation }\end{array}$ & $\begin{array}{c}\text { Standard } \\
\text { error of mean }\end{array}$ & $\begin{array}{l}95 \% \text { confidence } \\
\text { interval }\end{array}$ & $t$ value & Df & $p$ value \\
\hline Paired one & Pre- and post-operative walking distance & -442.00 & 189.00 & 44.51 & -535.58 to -347.76 & -9.92 & 17 & $<0.001$ \\
\hline Paired two & Pre- and post-operative NRS & 3.60 & 1.79 & 0.42 & $2.72-4.50$ & 8.57 & 17 & $<0.001$ \\
\hline
\end{tabular}

Series $1 \quad$ Series 2
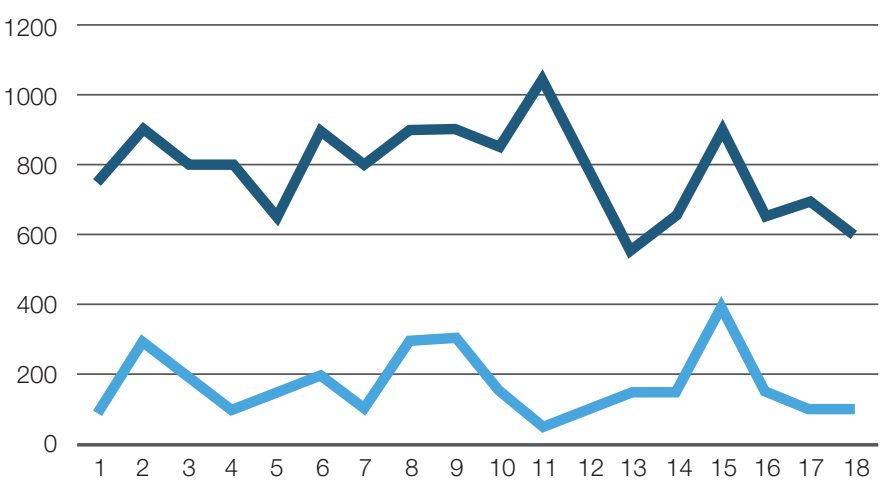

Figure 1. Series 1: Pre-operative walking distance;

Series 2: Post-operative walking distance

\section{Discussion}

In our study, we used two major criteria for identifying the degree to which the patient's life is affected by their disease. These criteria are pain score and walking distance. We consider the use of the Harris hip score to be inappropriate for and not easily applicable in our remote rural communities. Our patients generally have financial constraints and pay out of pocket for all surgeries. These procedures are not the first choice in our environment. The skills and instruments required to perform total hip replacements, vascularised fibula grafts and cement augmentation techniques are not readily available in this region of the world. Dislocation of the hips during the procedure was possible in only four of the 18 patients operated. The remaining patients had the neck of the femur osteotomised in situ. It was noted that the capsule of the hip joint was contracted in 14 patients. The medullary cavities were filled with thick unyielding debris which make reaming difficult and fraught with risk of perforation, with one patient having medial medullary wall perforation. Those whose femoral heads were able to be dislocated had more advanced femoral head collapse seen at the time of operation.

Medullary reaming was difficult in all but one patient. These findings are not commonly seen in patients who had either hemiarthroplasty or THR due to trauma. The mean post-operative walking distance was 614 metres indicating a more than three times improvement of the ability to walk long distances. The improvement was gradual and increased with time. The mean pre-operative NRS for pain was 6 with a range of 5 to 9 . The average post-operative NRS was 3 indicating a two-fold decline in intensity of pain when sitting or walking. Plots comparing the pre- and post-operative walking distances show patients with less favourable pre-operative walking distances having the greatest improvement in post-operative walking ability. There is a similar decline in pre-operative NRS for pain in patients with higher pre-operative NRS score (Figures 1 and 2). There is a definite and sustained clinical improvement in function and freedom from pain after bipolar hemiarthroplasty in all our patients. There were no significant complications in any patients except for one who had deep infection necessitating removal of the implant. Persistent thigh and hip pain was noticed in two patients who were controlled by non-steroidal analgesics. In a series of 17 and 13 patients followed over 2 years, the revision rate was $59 \%$ and $37 \%$ respectively. ${ }^{7-9}$ None of our patients needed revision.
Pre-operative NRS Post-operative NRS

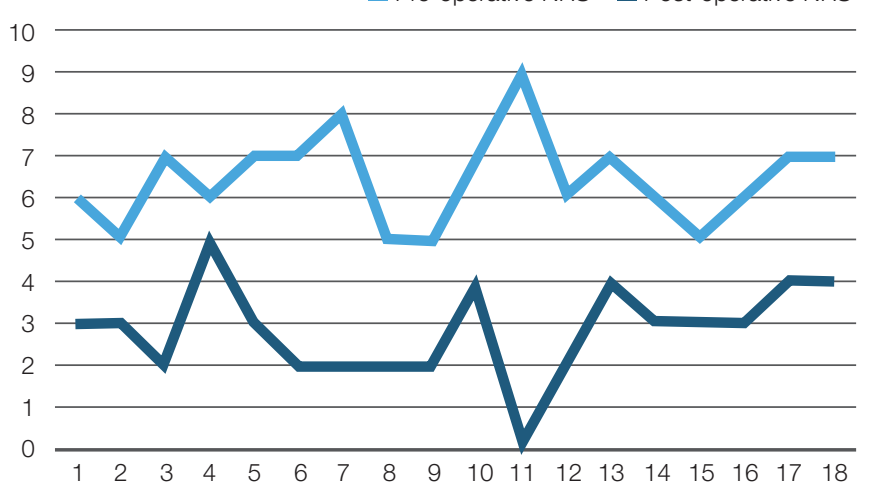

Figure 2. Pre- and post-operative NRS for pain

Femoral head preserving operations like autologous iliac bone grafts combined with muscle pedicle bone grafts and vascularised fibula strut graft are techniques that require a lot of patience and long periods of non-weight bearing..$^{9,10}$ The operations which preserve the femoral head include core decompression, and pedicled vascularised grafts. ${ }^{11}$ The bipolar hemiarthroplasty has been used extensively in treating elderly patients with intertrochanteric fractures with good success. Its use in treating patients with Ficat and Arlet stage III or lower patients has been popular in Nigeria for more than a decade. The majority of patients who underwent this operation had it for reasons of trauma. The assessment or those patients who had it for non-traumatic reasons generally did not have a Harris hip score as a pillar of pre-operative requirements because the operation is intended to deal with a fracture, unlike in patients who need hemiarthroplasty for diseases like osteoarthritis and aseptic necrosis due to many causes. The Harris scoring system may not be adaptable to an African environment where hardly any shoe-lacing, climbing of stairs or counting distances by blocks occur. ${ }^{12}$ We offer this study as a reference in the literature to what can be done for stage III AVNFH and to support the use of the simple bipolar hemiarthroplasty in the resource-constrained environment.

\section{Compliance with ethics guidelines}

Ethical clearance for the study was obtained at the Federal Medical Centre, Katsina.

\section{References}

1. J Makani, SF Ofori-Aquah, O Onodu, A wonkam, K Ohene-Frempong. Sickle cell disease: new opportunities and challenges in Africa. 2013 The Scin World Jour http:dx.doi.org/10.115/2013/193252 Accessed 23/06/2016.

2. Al-Mousawi A, Maliki A, Al Aradi M, Al Bagali A, Al Sadadi, MMY Booz. Total hip replacement in sickle cell disease. International Orthopaedics (SICOT) 2002;26:157-61.

3. Sung-Kwang Chun, Jae-Young Hong, Sang-Hwan Han, Jun-Kyu Moon, Channg-Young Hur, Wong-Yong Shon. Results of sugiokas transtrochanteric osteotomy for osteonecrosis of the femoral head. J Korean Orthop Assoc 2008;43(2):213-19.

4. Ficat RP. Idiopathic bone necrosis of the femoral head. Early diagnosis and treatment. J Bone Joint Surg Br 1985 Jan;67(1):3-9. 
5. P Hernigou, D Bachir, F Galacteros. Avascular necrosis of the femoral head in sickle cell disease: treatment of collapse by the injection of acrylic cement. J Bone Joint Sur 1993;75B(6):875-80.

6. Steinberg ME. Core decompression of the femoral head for avascular necrosis: Indications and results. Can J Surg. 1995 Feb;38 Suppl 1:S18-24.

7. Y Hasegawa, H Iwata, S Toril, Iwase T, K Kawamoto SIwasada. Vascularised pedicle bone grafting for nontraumatic avascular necrosis of the femoral head. A 5-11 year follow-up. Archives of Orthopaedic and Trauma Surgery 1997;116(5):251-58.

8. Lihong Fan, Xiaogian Dang, Kunzheng Wang. Comparison between bipolar hip arthroplasty for unstable intertrochanteric fractures in elderly osteoporotic patients. Plos One 2012;7(6):e39531.

9. Crues R. Cortisone-induced avascular necrosis of the femoral head. $J$ Bone Joint Surg (Br) 1977; 59-B:308-17.

10. Clarke HJ, Jinnah RH, Brooker AF, Michaelson JD. Total replacement of the hip for avascular necrosis in sickle cell disease. J Bone Joint Surg (Br) 1989;71-B:465-70.

11. Meyers $\mathrm{MH}$. The treatment of osteonecrosis the hip with fresh osteochondral grafts and with muscle pedicle graft technique. Clin Orthop 1978;130:202-209.

12. Sodderman $P$, Malchau $H$. Is Harris hip score system useful to study the outcome of total hip replacement? Clin Orthoprel Res 2001; 384:189-97. 